\title{
SPIN-GLASS ORDERING AND
}

\section{SUPERCONDUCTIVITY IN AMORPHOUS}

$\mathrm{La}_{80} \mathrm{Au}_{20}$ ALLOYS DTOPED WITH Gd

S. J. Poon and J. Durand

JANUARY 1977

A REPORT ON RESEARCH CONDUCTED

UNDER CONTRACT FOR THE

U.S. ENERGY RESEARCH AND DEVELOPMENT

ADMINISTRATION

RERTHED DOCU:..EEUT(S) REVIEWED PATEATWISE:

NO OBIECION IS WITEDOSOSD FROA THE PATENT

STAILPOINT TO PUBLICATION THEREOF.

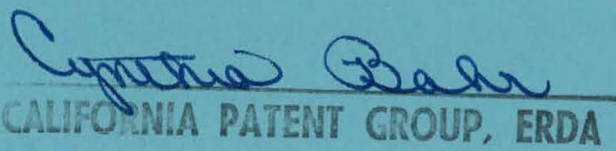

W. M. KECK LABORATORY OF

ENGINEERING MATERIALS

CALIFORNIA INSTITUTE OF TECHNOLOGY

PASADENA 


\section{DISCLAIMER}

This report was prepared as an account of work sponsored by an agency of the United States Government. Neither the United States Government nor any agency Thereof, nor any of their employees, makes any warranty, express or implied, or assumes any legal liability or responsibility for the accuracy, completeness, or usefulness of any information, apparatus, product, or process disclosed, or represents that its use would not infringe privately owned rights. Reference herein to any specific commercial product, process, or service by trade name, trademark, manufacturer, or otherwise does not necessarily constitute or imply its endorsement, recommendation, or favoring by the United States Government or any agency thereof. The views and opinions of authors expressed herein do not necessarily state or reflect those of the United States Government or any agency thereof. 


\section{DISCLAIMER}

Portions of this document may be illegible in electronic image products. Images are produced from the best available original document. 


\section{California Institute of Technology}

W. M. Keck Laboratory of Engineering Materials

\section{SPIN-GLASS ORDERING AND SUPERCONDUCTIVITY IN AMORPHOUS ${ }_{\text {La }}{ }_{80} \mathrm{Au}_{20}$ ALLOYS DOPED WITH Gd \\ by}

S. J. Poon and J. Durand

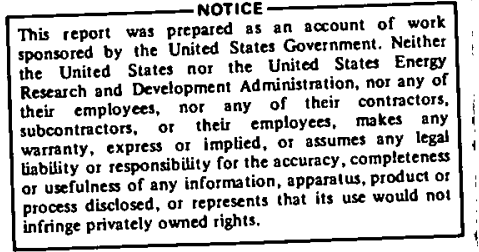

Energy Research and Development Agency Report No. 81, under Contract No. $\mathrm{AT}(04-3)-822$.

Professor Pol Duwez, principal investigator.

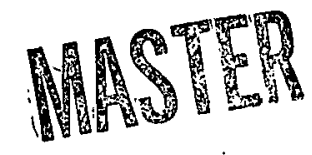

DISTRIBUTION OF THIS DOCUMENT IS UNLIMITED 


\begin{abstract}
NOTICE
This report was prepared as an account of work spunsured by the United States Government. Neither the United States nor the Energy Research and Development Administration, nor any of their employees, nor any of their contractors, subcontractors, or their employees, makes any warranty, express or implied, or assumes any legal liability or responsibility for the accuracy, completeness or usefulness of any information, apparatus, product or process disclosed, or represents that its use would not infringe privately-owned rights.
\end{abstract}




\begin{abstract}
Magnetization and resistivity measurements are performed on amorphous $\mathrm{La}_{80} \mathrm{Au}_{20}$ alloys doped with Gd impurities. The anomalous behavior observed in the dependence of the superconducting transition temperature on Gd concentration is related to the onset of spin-spin correlations among the Gd impurities. We have identified the coexistence of superconductivity and magnetic ordering as a spin glass.
\end{abstract}


It was reported ${ }^{1-5}$ that for several alloys systems the superconducting transition temperature $\mathrm{T}_{\mathrm{c}}$ instead of decreasing monotonically with increasing impurity concentration, exhibits an anomalous peak close to the Abrikosov-Gor'kov critical concentration $x_{A G}$. This behavior was attributed to a magnetic ordering of the impurity spins in the vicinity of the peak. ${ }^{6-8}$ Low field magnetization was used to probe the type of magnetism involved. $2,4,9$ However, the data obtained so far only imply the occurrence of antiferromagnetism of some sort: either a Kondo effect or an antiferromagnetic interaction among impurities, which has significantly different influence on the superconductivity around $x_{A G} \cdot 10$ In amorphous alloys, the interaction between magnetic impurities via conduction electrons is attenuated while the spin-orbit coupling is significantly enhanced. 11 The former effect which tends to enhance the spin-flip scattering ${ }^{6}$ can be isolated as the latter suppresses the effect of the local exchange field on Cooper pairs. ${ }^{12} \mathrm{By}$ using both magnetization and resistivity measurements on amorphous superconductors doped with magnetic impurities, we can clarify the type of magnetic ordering coexisting with a superconducting phase. Comparison with existing theories on the effects of spin-spin correlations on superconductivity is thus possible.

Sample foils of nominal composition $\mathrm{La}_{80-\mathrm{x}} \mathrm{Gd}_{\mathrm{x}} \mathrm{Au}_{20}(\mathrm{x}=0,0.24,0.42$, $0.5,0.55,0.59,0.63$ and 0.67 ) were prepared in the usual way as dis cussed elsewhere. ${ }^{13}$ The amorphousness of each foil was checked by $\mathbf{x}$-ray diffraction. Low field susceptibility measurements were made by the ac inductance method down to $1.3^{\circ} \mathrm{K}$. Detailed magnetization measurements on four alloys $(x=0,0.24,0.5$ and 1.0$)$ were made between $1.8^{\circ} \mathrm{K}$ and $290^{\circ} \mathrm{K}$ in fields up to $70 \mathrm{kOe}$ using the Faraday method. 13 
Resistivity measurements were performed between $1.3^{\circ} \mathrm{K}$ and $20^{\circ} \mathrm{K}$ by the standard four probe technique. The $\mathrm{La}_{80} \mathrm{Au}_{20}$ matrix was found to contain $\sim 0.02$ at. $\% \mathrm{Gd}$. The superconducting transition temperature $\mathrm{T}_{\mathrm{c}}$ (transition width $\sim 0.2^{\circ} \mathrm{K}$ ) was determined consistently for each sample by adopting the mean-field $T_{\text {. }}$ extrapolated from the onset of superconductivity.

In figure $1, T_{c}$ values of at least two samples for each nominal composition (within \pm 0.01 at. $\%$ uncertainty) is represented by a two dimensional uncertainty bar. Comparison with the Abrikosov-Gor'kov curve is made by fitting the low Gd concentration data to theory. Thus, the $\mathrm{T}_{\mathrm{c}}$ of pure amorphous $\mathrm{La}_{80} \mathrm{Au}_{20}$ alloy is estimated to be $3.6^{\circ} \mathrm{K}$, and the critical concentration $x_{A G}$ extrapolated to 0.7 at. $\%$ Gd. For $x=0.59, T_{c}$ is observed to exceed the $A G$ value $T_{A G}$ by $\sim 0.16^{\circ} \mathrm{K}$. Unfortunately, we were not able to measure $T_{c}$ below $1.3^{\circ} \mathrm{K}$ for higher Gd concentrations. However, the $\mathrm{T}_{\mathrm{c}}$ of $\mathrm{x}=0.63\left(\sim 1.15^{\circ} \mathrm{K}>\mathrm{T}_{\mathrm{AG}}=0.94^{\circ} \mathrm{K}\right)$ can be estimated from the onset of superconductivity transition around $1.35^{\circ} \mathrm{K}$ which is compared with other samples with measurable $\mathrm{T}_{\mathrm{c}} \cdot \mathrm{Th}$ latter demonstrate similar resistivity behavior around $T_{c} \cdot$ Resistivity minima are observed at $\mathrm{T} \sim 8^{\circ} \mathrm{K}$ for the $\mathrm{x} \gtrsim 0.42$ alloys.

At low temperature $\left(\mathrm{T}<20^{\circ} \mathrm{K}\right)$, the initial susceptibility can be fitted to a Curie-Weiss law $x_{0}=C /(T+\theta)$ with the values of $\theta$ included in figure 1. It can be seen that the values of $T_{c}$ are enhanced around the region where the $A G$ curve intersects the $\theta$ line. We fitted the magnetization data to a Brillouin function of the form $M(H, T)=M(\infty, 0) B_{J}(\mu H /(T+\theta))$. The value of $J$ determines the average spin value of the polarization 'clouds'. 14 Such plot for the 0.24 sample $(\mathrm{g}=2, \mathrm{~J}=4.35)$ is shown in figure 2 . Within experimental 


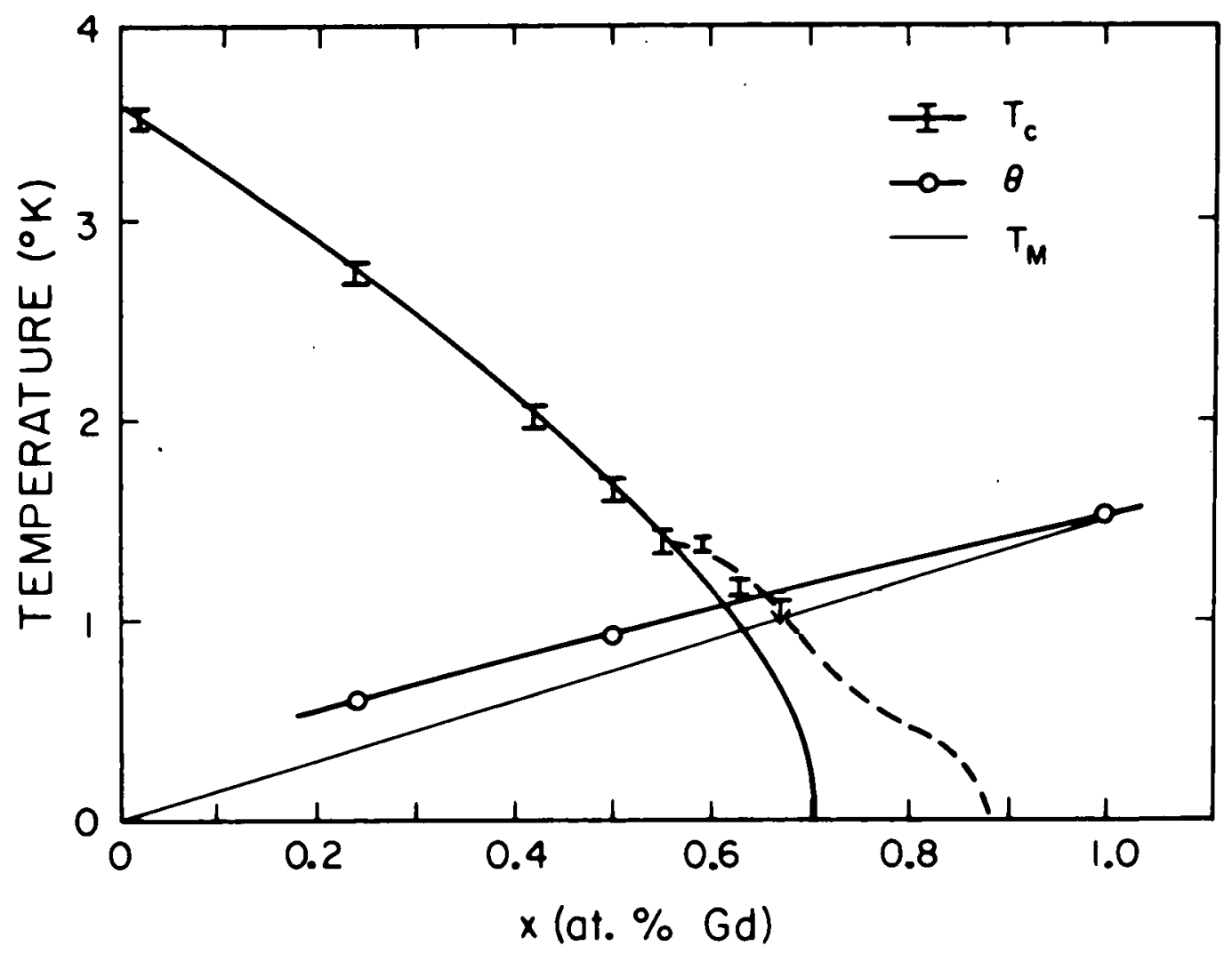

Fig. 1. $T_{c}{ }^{\prime} T_{M}$, and $\theta$ vs Gd composition. The solid line $工$ is obtained from the $A G$ theory, dashed line is derived from the Bennemann theory. 


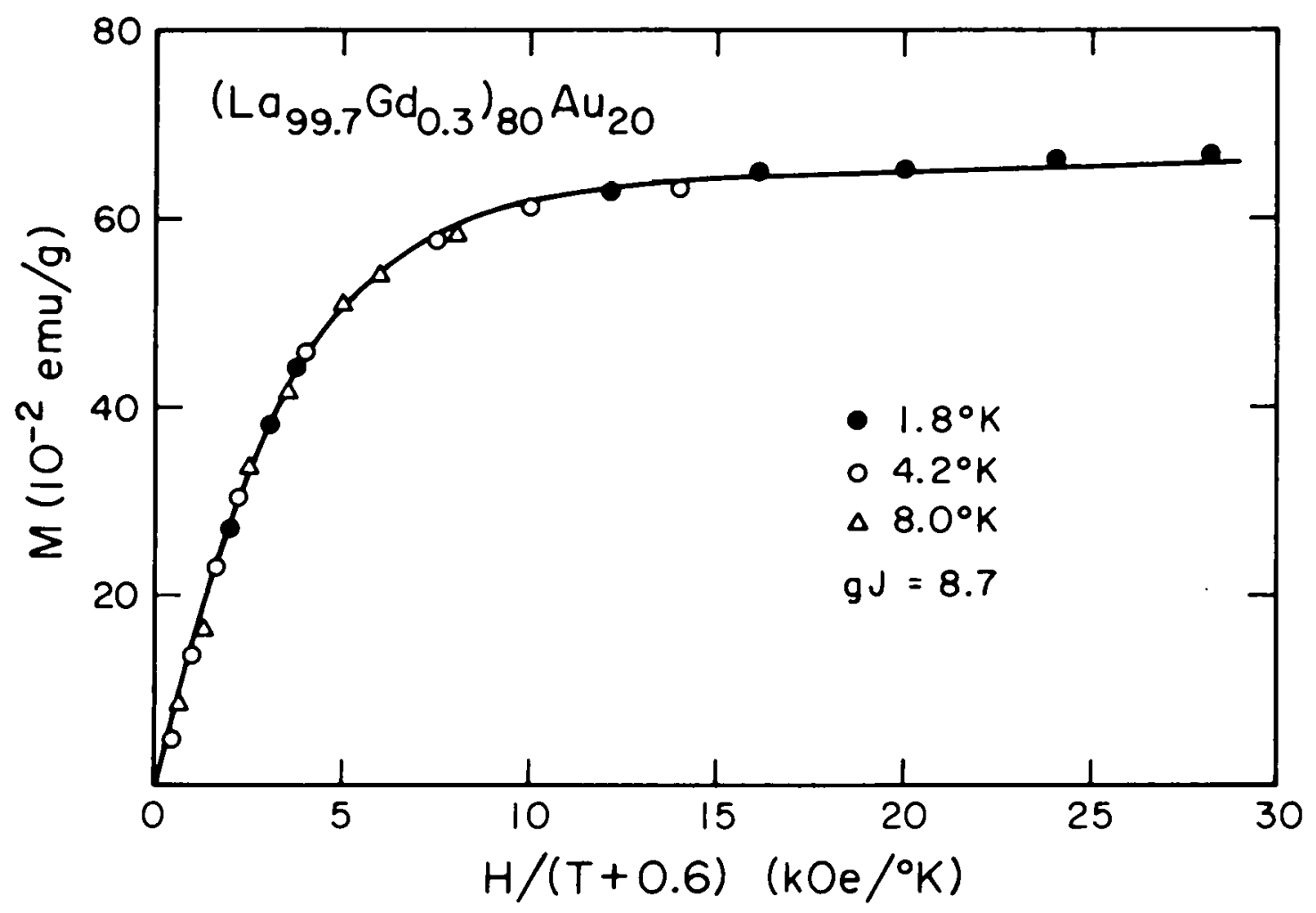

Fig. 2. Variation of the magnetic impurities magnetization vs $\mathrm{H} /(\mathrm{T}+0.6)$ for a $0.24 \%$ sample. Full line represents a Brillouin function ( $g=2, J=4.35$ ). 
error, the $\theta$ values so determined agree well with those obtained from low temperature $x_{0}$. Such positive values of $\theta$ indicate an antiferromagnetic coupling of some sort among the Gd atoms carrying a moment close to the ionic value in the low concentration limit.

A more accurate insight on the nature of the magnetic ordering may be obtained from two supplementary experimental facts. First, for a $4 \%$ sample, we observe a susceptibility maximum at $T_{M}=1.9^{\circ} \mathrm{K}$ while low temperature $x_{0}$ also gives $\theta=1.9^{\circ} \mathrm{K}$. Similar result is observed for a $1 \%$ sample. The linearity of $T_{M}$ as a function of $x$ at low concentration gives values reasonably close to those obtained for $\theta$, as shown in figure 1. Second, we obtain scaling laws in the magnetization and susceptibility of the form $M / x=f(H / x, T / x)$ and $x_{0}=g(T / x) .13$ The scaling behavior ${ }^{15}$ so observed originates from the $1 / r^{3}$ dependence of the long-range pairwise interaction between Gd impurities. The latter is made possible in an amorphous matrix probably due to the polarization of La atoms with an empty f-band. 16 Thus, the values of $\theta$ are characteristic of a spin-glass transition temperature in the restricted sense. 15

The pair breaking parameter in the AG theory was modified by Fulde and $\mathrm{Maki}^{12}$ as $\alpha=\left(\hbar / \tau_{\mathrm{s}}+\mathrm{I}^{2} \tau_{\mathrm{so}} / 2 \hbar\right)$, where the mean exchange field $I \sim\left\langle J_{z}\right\rangle, \tau_{s}$ and $\tau_{\text {so }}$ are the spin-flip and spin-orbit scattering time respectively. It was shown from upper critical field measurements 11 that $\tau_{\text {so }}$ is rather small in amorphous ${ }^{\mathrm{La}}{ }_{80} \mathrm{Au}_{20}$ alloys, and that $I \sim\left\langle\mathrm{J}_{\mathbf{z}}\right\rangle=0$ when the spins start to order antiferromagnetically. The latter is valid since the mean-free-path limited coherence length $\xi \approx 100 \AA^{11}$ is significantly greater than the spin-spin correlation distance $l_{s} \approx 20 \AA$ for the $0.6 \%$ sample. The pair breaking parameter 
then reduces to $\alpha=\hbar / \tau_{s}$. Bennemann ${ }^{6}$ pointed out that the spin-flip scattering time $\tau_{s}$ is reduced by a factor $J /(J+1)$ between the randomly oriented spins and the ordered spins in the limit of very high local exchange fields acting between the ions. In the present case, one would expect an enhanced critical concentration of $\sim 0.88$ at. $\%$ Gd. From high field magnetization data on the $0.5 \%$ sample, we deduced ${ }^{13}$ an average local field of $\sim 4 \mathrm{kOe}\left(\right.$ or $0.5^{\circ} \mathrm{K}$ ) which obviously violates the high field assumption at $\sim 1^{\circ} \mathrm{K}$. Instead, smaller enhanced $T_{c}$ values are expected around $x \sim 0.6$ at. $\% \mathrm{Gd}$. The theoretical $T_{c}$ enhancement based on the Bennemann theory ${ }^{6}$ is plotted in figure 1. Without crystalfield splitting, the initial depression $-\left(\mathrm{dT}_{\mathrm{c}} / \mathrm{dx}\right)_{\mathrm{x}=0} \approx 3.6^{\circ} \mathrm{K}$ per at. $\% \mathrm{Gd}$ yields a value of the exchange interaction paramete $\mathrm{r}|\mathrm{J}| \approx 0.16 \mathrm{eV}$. Similar value of $\left|J_{s f}\right|=0.14 \mathrm{eV}$ due to indirect exchange interaction was obtained from high field measurements. 13 The presence of a resistivity minimum at $\mathrm{T} \sim 8^{\circ} \mathrm{K}$ for $\mathrm{x} \gtrsim 0.42$ implies that $\mathrm{J}_{\mathrm{sf}}$ is negative in sign. Beyond the first Born approximation, a more rapid depression of superconductivity a round $x \geq x_{A G}$ is thus expected. In fact, such effect was observed in crystalline LaGd alloys. 1

From magnetization measurements, we have demonstrated unambiguously the existence of a spin-glass regime within the superconducting phase in amorphous La-Gd-Au alloys. This allows us to clarify the type of magnetic ordering which is favorable for the enhancement of superconductivity.

ACKNOWLEDGMENT: The authors wish to thank Professor Pol Duwez for his interest and support throughout this work. 


\section{REFERENCES}

* Work supported by the Energy Research Development Agency, Contract No. $\mathrm{AT}(04-3)-822$.

† On leave from Laboratoire de Structure Electronique des Solides, $E_{0} R_{0} A .100,4$, rue Blaise Pascal, 67000 Strasbourg, France.

1. Hein, R. A., Falge, R. L., Matthias, B. T., and Corenzwit, C., Phys. Rev. Lett. 2, 500 (1959).

2. Guertin, R. P. and Parks, R. O., Solid State Comm. 7, 59 (1969).

3. Hauser, J. J., Robbins, M., and DiSalvo, F. J., Phys. Rev. B $\underline{8}$, $1038(1973)$

4. Morris, R. C., Phys. Rev. Lett. 34, 1164 (1975).

5. Zimmermeyer, G. and Roden, B., Z. Physik B24, 377 (1976), and references cited therein.

6. Bennemann, K. H., Phys. Rev. Lett. 17, 438 (1966).

7. Entel, P. and Klose, W., J. Low Temp. Phys. 17, 529 (1974).

8. Klose, W., Entel, P., and Nohl, H., Phys. Lett. 50A, 186 (1974).

9. Peter, M. et al, Helv. Phys. Acta 44, 345 (1971).

10. For recent reviews, see Maple, M. B., and Fisher, $\varnothing$ and Peter, M., p. 289 and p. 327 in Magnetism V edited by Rado, G. T. and Shul, H., Academic Press, New York, 1973. 
11. Johnson, W. L., Poon, S. J., and Duwez, P., Phys. Rev. B11, $150(1975)$.

12. Fulde, P. and Maki, K., Phys. Rev. 141, 275 (1966).

13. Poon, S. J. and Durand, J., to be published (1976).

14. Muellner, W. C. and Kouwel, J. S., Phys. Rev. B 11, 4552 (1975) and references cited therein.

15. Souletie, J. and Tournier, R., J. Low Temp. Phys. 1, 95 (1969).

16. Blandin, A., in ref. 10, p. 57 . 